\title{
La valoración social de la zona infantil del parque Morelos, pertenencia y protección del patrimonio moderno
}

Juan Christopher Alcaraz Padilla

Universidad de Guadalajara

\section{Resumen}

La identidad y pertenencia que los espacios urbanos ayudan a construir en los grupos sociales que habitan las comunidades donde estos se establecen provocan la necesidad de resaltar su valoración desde el punto de vista social y, con ello, buscar su preservación. En el presente artículo se rescata esta idea soportada por un breve marco teórico brindando los fundamentos y conceptos básicos para entrar en materia respecto a un referente particular: las esculturas de juego del parque Morelos. La historia de este espacio sociocultural se toma como ejemplo del impacto y valor que los espacios públicos, tanto el parque como particularmente las esculturas diseñadas por Fabián Medina Ramos, tienen en la comunidad. Este artículo relata las diferentes intervenciones hechas por parte del gobierno y cómo el papel de los actores sociales que conviven en el lugar fue fundamental para el diseño de propuestas de renovación o restauración integrales.

Palabras clave: Valoración social, parque Morelos, patrimonio moderno.

\section{Abstract}

The identity and belonging that urban spaces help to build in the social groups that inhabit the communities where they are established provoke the necessity of highlighting their valuation from a social point of view and thus, seek their preservation. In the present article this idea is revisited, supported by a brief theoretical framework providing the foundations and basic concepts to enter the subject regarding to a particular reference: the play sculptures of Parque Morelos. 
The history of this sociocultural space is taken as an example of the impact and value that public spaces, both the park and particularly the sculptures designed by Fabián Medina Ramos, have on the community. This article recounts different interventions made by the government and how the role of the social actors living in the place was fundamental for the design of renovation or restoration proposals.

Key words: Social value, Morelos park, modern heritage.

\section{Introducción}

El patrimonio, en sus distintas variables, solicita ser resguardado y protegido. Las intervenciones e investigaciones, enfocadas a la valoración, han mostrado la importancia de la aceptación de los actores sociales del lugar para su conservación y difusión de atributos tangibles e intangibles a las siguientes generaciones. El sentido de pertenencia y apego generan el resguardo de la herencia histórica, artística y cultural del caso de estudio. El patrimonio artístico o moderno, pertenecientes al siglo xx, está limitado en protección y reconocimiento. Dicha obra, por su temporalidad, es susceptible a cambios que pueden alterar parcialmente o totalmente la lectura del lugar y su correlación sociocultural.

El Parque Morelos, antigua Alameda de la ciudad de Guadalajara, posee un espacio peculiar, el conjunto de la zona infantil o, también conocido como, esculturas juego, consumada en la segunda mitad del siglo xx. El desconocimiento de su valor lo llevó a estar en riesgo de desaparecer por las obras municipales del periodo 2017-2018 bajo su esquema de rescate de espacios públicos. Sin embargo, la sociedad externó su inconformidad y realizó labores de protección demostrando su pertenencia del lugar a la par del valor social que el conjunto posee.

El objetivo de la investigación es mostrar como la valoración social de los habitantes y usuarios del parque ayudó al sentido de pertinencia y la protección del conjunto como parte de su patrimonio artístico urbano.

\section{Identidad, pertenencia y protección del patrimonio artístico urbano}

La relación social entre los diversos sectores de la ciudad, en especial los espacios públicos, generan significados que, al tiempo, son parte de la identidad que se entiende como algo «específico de cada lugar que es abordada desde la noción de la pertenencia. Esta última muestra el carácter concreto del espacio al implicar en cada lugar su orden y elementos característicos con aquello que lo configura y lo hace ser de tal forma» (De las Rivas, 1992, p.38). La identidad del es- 
pacio público puede variar conforme a su temporalidad, significados, localización, manifestaciones socioculturales y percepción personal.

En los espacios públicos, la identidad se encuentra mayormente remarcada por los elementos simbólicos otorgados por sus usuarios. Cada experiencia vivida marca, en cierto modo, la forma de habitar en el espacio y proporciona un nuevo significado. Es allí que el simple espacio «se transforma en lugar, cuando estos fenómenos socio-espaciales se materializan en espacios limítrofes, ya sea de manera física o conceptual dentro del espacio construido, y su impacto reflejan la identidad, la concepción simbólica y la personalidad de quien los habita, las cuales son manifestadas en conductas vinculadas a la tolerancia y cercanía con otras personas, delimitadas por el espacio personal» (Bernal, 2016, p.174).

El sentirse identificado con un lugar determinado genera el sentido de pertenencia. Este concepto lo define la Real Academia Española como la «relación de una cosa con quien tiene el derecho de ella». Los espacios públicos, al pertenecer al bien común, son por decreto libres de ser transitados y utilizados siempre y cuando no se dañe o ponga en peligro la integridad física y moral del lugar y sus usuarios. La pertenencia del lugar da paso a la apropiación misma que «se relaciona con la temporalidad, la acción práctica del presente, desde donde se ve al otro o se puede apreciar de una forma particular el mundo. El espacio de la experiencia empírica supone el manejo de las distancias sociales y efectivas mediante la proxémica y la territorialidad» (Bernal, 2016, p.178). Por lo general, se busca que la apropiación no sea invasiva o altere las dinámicas a las que está destinado el lugar. Asimismo, se enfoca en el cuidado y protección del espacio público y sus actividades colectivas.

La protección de los espacios públicos se ha convertido en un tema común para los habitantes y administraciones gubernamentales. Como se ha mencionado, todos tienen derecho al uso de los lugares del bien común. Pero, el albergar diversos usuarios que desconocen o no toman en cuenta su relevancia llega a generar un deterioro físico que trae consigo patologías urbanas que pueden resultar en el abandono e incuria. La protección de los espacios públicos va desde el mantenimiento paulatino, especialmente si estos poseen áreas verdes, hasta el impedir acciones discordantes como demoliciones o retiro de manifestaciones socioculturales. El resguardo del espacio público y sus componentes se genera a partir de la identidad, el apego al lugar y el sentido de pertenencia. La salvaguarda está principalmente regulada por las instancias públicas de los distintos niveles de gobierno. Aunque, en ciertas circunstancias, donde el espacio público está inserto en un contexto patrimonial, la vigilancia y denuncia se genera en mayor medida por los habitantes del lugar o asociaciones vecinales y civiles.

El término patrimonio es amplio y abarca no sólo lo físico sino también lo denominado intangible. El patrimonio urbano se puede entender como «un espacio para los usos sociales jugando así un rol en la consecución de sentido de pertenencia. En tanto presenten condiciones para los usos sociales, vale decir que cuenten con espacios para que las mayorías puedan aprovecharlas y encontrarlas significa- 
tivas, las plazas jugarían un rol en relación a la formación de sentido de pertenencia» (Weibel, 2018). El patrimonio edificado se divide en tres grupos universales: arqueológico, histórico y artístico. Cada uno de ellos pertenece a una temporalidad determinada y los grados de protección varían según su clasificación. La arquitectura producida durante el siglo xx se cataloga en los bienes artísticos que comprenden «monumentos, las pinturas murales y las esculturas integradas a edificios públicos o centros de reunión, públicos o privados, ejecutadas en tiempos recientes y que por ellos aún no hubieran sido valoradas estéticamente» (Cottom, 2008, p.266).

El patrimonio moderno, por su temporalidad, ha sido sujeto de modificaciones parciales o totales. Al pertenecer a una clasificación de características ambiguas la hace susceptible, «su protección legal es débil o inexistente, y el aprecio de la comunidad hacia él es deficiente con frecuencia» (Allier, 2006, p.46). En los espacios públicos dentro de contextos patrimoniales se encuentran elementos que pasan desapercibidos por los habitantes y las autoridades. El deterioro que se presentan es por la falta de protección y difusión de la relevancia que poseen. «Los bienes artísticos tienen importancia como testimonio del desarrollo estético de un pueblo en el transcurso del tiempo» (Becerril, 2003, p.11). El patrimonio moderno requiere de mecanismos para su clasificación y protección, «como criterios iniciales para clasificar y evaluar el patrimonio moderno, se plantean los siguientes aspectos: el uso de nuevos materiales, tecnología, conceptos de producción, transporte comunicación y de trabajo, la organización del espacio y, eventualmente, la implementación y materialización a través de la planeación, diseño y construcción» (Allier, 2006, p.46).

En el marco del patrimonio moderno, las esculturas han sido mayormente propensas a daño físico por vandalismo y abandono. La imagen de los elementos compositivos del espacio público causa, en el imaginario social, una perspectiva del lugar donde si es negativo, se procura evadir y transitar, en consecuencia, las patologías urbanas incrementarían sustancialmente y atraería a otro sector de usuarios y actividades discordantes, "cuando el deterioro causa problemas en el uso del espacio público, la agresión se hace evidente y el usuario tiende a alejarse del sitio si tiene otras opciones de espacio en donde realizar sus actividades. Esta inserción del sitio puede desencadenar un círculo vicioso de avance del deterioro y de mayor abandono» (Velasco, 2015, p.89-90).

El desafío del patrimonio moderno no solamente surge a partir del vandalismo e incuria, las incursiones gubernamentales que buscan marcar sus acciones con frecuencia atentan, sin distinción, contra edificaciones y espacios públicos. Los elementos arquitectónicos y escultóricos modernos en contextos patrimoniales requieren ser denotados bajo su relevancia histórica, artística y tecnológica. Una manera de vislumbrar dichos atributos se obtiene por medio de la valoración que busca el reconocimiento por parte de la sociedad, vecinos o actores sociales del lugar. 


\section{La valoración social del patrimonio moderno}

El establecer el valor, en términos cualitativos, conlleva a primeramente visualizar que atributo se requiere resaltar. Joseph Ballart refiere al valor como «una cualidad añadida que los individuos atribuyen a ciertos objetos que los hacen merecedores de aprecio. Estamos, pues, ante un concepto relativo que aparece y desaparece en función de un marco de referencias intelectuales, culturales, históricas y psicológicas, que varían según las personas, los grupos y las épocas» (Ballart, I996, p.215). La definición del valor comenzó a ser vista por parte del icomos (Consejo Internacional de Monumentos y Sitios) cuando acreditó Las normas de Quito en el año de 1964. El valor dejó de ser un concepto y pasó a ser una acción que «equivale a habitarlo en las condiciones objetivas y ambientales que, sin desvirtuar su naturaleza, resalten sus características y permitan su óptimo aprovechamiento» (Gómez, 2009, p.294) Los valores a los que se aluden pueden ser múltiples. Sin embargo, el hecho de que únicamente se posea uno no quiere decir que sea menos importante que otro con mayor número peculiaridades, teniendo en cuenta que se valora en relación con lo que se requiere destacar.

La valoración como método de defensa del patrimonio consiste en una investigación previa al proyecto de intervención. El recurrir a los distintos atributos que posee el lugar, tiene como objetivo mostrar la relevancia de lo que se pretende proteger. En algunas ocasiones, la solución no es modificar el espacio, sino fortalecer las relaciones del lugar con el entorno y sus habitantes. La distinción de cada valor, obedece a procesos peculiares, que generalmente parten del ámbito histórico, artístico y social. Un objeto, espacio o manifestación sociocultural puede tener un valor patrimonial por su permanencia a través del tiempo y en la memoria colectiva de la sociedad.

La complejidad de valorar, no es una limitante que, en un todo, resulte poco práctico o inalcanzable. Al contrario, la búsqueda por descubrir los detalles característicos aporta sustancialmente a la comprensión del lugar, las necesidades específicas a intervenir o la difusión. El patrimonio a valorar no se engrandece por el número de atributos. Existen escenarios donde sólo un detalle se puede generar una propuesta esencialmente benéfica. La distinción entre valores es indispensable ya que cada uno corresponde a una cualidad particular. La clasificación de los diversos atributos suele ser distinta con respecto al autor que los utiliza.

Por lo general, los valores de mayor concurrencia son los relacionados con la historia, la estética y el arte. A partir de ellos se desprenden distintas variables aplicables al caso de estudio entendiendo que los valores son "productos de la mente humana, basados en parámetros que se encuentran en los contextos relevantes socio-cultural y físico. Son producto de los procesos de aprendizaje y necesitan ser renovados por cada generación de individuos; por consiguiente, no son estáticos, sino que están sujetos a cambio a través del tiempo. De hecho, como es obvio, los valores no están embebidos en los objetos 
patrimoniales, sino asociados a éstos por medio de las comunidades o de los individuos» (Jokilehto, 20I6, p.26). La interacción diaria entre el usuario y el lugar no sólo genera una identidad y apego, también, producen características simbólicas y significativas que se traducen en actividades y tradiciones que trascienden a otras generaciones.

El patrimonio urbano no sólo tiene valores históricos, al contrario, puede adquirir otros, tal es el caso de los espacios públicos y su interacción con sus usuarios donde se genera un valor social. Dicho atributo comprende «las propiedades que convierten a un lugar en el núcleo de manifestaciones y actividades sociales, culturales, religiosas, entre otras y lo dotan de un simbolismo que da valor y propician estas concentraciones de personas. El valor social es intangible, pero no por ello menos importante y por lo mismo, más sensible a los cambios que pueda haber en la configuración y materia física de los bienes en cuestión» (Suárez, 20I6, p.42). En el caso de los espacios públicos, los significados simbólicos que otorga el colectivo social son los puntos a destacar en la valoración. Es imprescindible recurrir a este valor ya que se enfoca a las necesidades particulares de los usuarios.

La importancia de la valoración social se relaciona con la protección y cuidado que se le pueda dar por parte del colectivo a una zona específica. De igual forma, ayuda a establecer lasos entre las personas con un fin en particular, mantener su espacio activo. En la práctica cotidiana, se olvida o pasa por alto las necesidades sociales en lo particular cuando se propone una intervención. Las administraciones gubernamentales suelen iniciar labores de construcción sin un previo análisis del contexto y las actividades que se realizan dentro de estos lugares. El enfoque principal, de acuerdo a ellos, es para la sociedad en general. No obstante, antes de buscar el bien de una mayoría se tendría que revisar las necesidades particulares de los habitantes que conviven diariamente con el espacio y sus componentes urbano-arquitectónicos. Durante el proceso de obra se ha observado el retiro de objetos y espacios que, en su momento, fueron relevantes y parte fundamental de las actividades, provocando una desarticulación y cambio de perspectiva del lugar. Entonces, aquello que brindaba un valor social al lugar deja de serlo y, el usuario recurre a otros puntos que pueda ofrecer la localidad, repercutiendo en un susceptible abandono.

La valoración social, como proceso intangible y subjetivo generador de pertinencia y protección de espacios públicos patrimoniales, resulta en un componente relevante que puede cambiar la visión de los trabajos propuestos por el sector público o privado. En el caso del primero, como se ha comentado, primordialmente busca manifestar las acciones de la administración en turno dejando a un lado las necesidades de la comunidad y transformando su espacio indiscriminadamente donde ya existen manifestaciones y actividades colectivas que han permanecido a través del tiempo. Una situación particular sucedió en el Parque Morelos de la ciudad de Guadalajara, donde los habitantes del contiguo barrio, El Retiro, y otras personalidades, mostraron ante la municipalidad y otros organismos el valor social que tiene un peculiar conjunto de esculturas que estuvo a punto de desaparecer por un proyecto de orden público. 


\section{La Alameda de la ciudad de Guadalajara}

El Parque Morelos, localizado al nororiente del primer cuadro de la ciudad de Guadalajara, ha trascendido por más de dos siglos. El valor histórico que adquiere es tan sólo el inicio de una serie de cualidades que, a través del tiempo, han ido creciendo gradualmente. Desde su fundación como la antigua Alameda hasta el hoy Parque Morelos se han acumulado diversas manifestaciones socioculturales que eventualmente quedan en la memoria colectiva, creando así una cantidad de símbolos y significados para los habitantes. Cada época tiene su valor social único, Para la sociedad, durante los siglos XVIII a principios del xx, la Alameda simbolizó aquel paseo con áreas verdes para la ciudad novohispana. La aparición de la Alameda fue aproximadamente en la segunda mitad del siglo xviri. La ordenanza de la Nueva Galicia señalaba la construcción de él. Sin embargo, no da por hecho la fecha de inicio de las obras o de la fundación de este espacio, pero si insinúa que se trabajó Inclusive en el apartado denominado Alameda, artículo 114, se señala las primeras incursiones de este lugar en la ciudad:

Por cuanto de día en día va creciéndose y aumentándose en gran manera el vecindario de esta ciudad, y hasta el presente no se han puesto en ella, recreaciones públicas, honestas, que para la diversión de los vecinos, se juzgan, no solo útiles, sino necesarias, sin embargo de haberlo solicitado los señores Presidentes; se ordena que el Procurador Mayor, tenga cuidado de hacer que la Alameda que se está formando a expensas del mismo vecindario, no descaezca y se procure un mayor aumento, haciendo que se planten árboles, que requiere, los que diariamente se rieguen, y se cultiven, para cuyo efecto se solicitará persona; que viviendo en ella la cuide a quien en caso de permitir, o que se arranquen los árboles o que se entren algunas bestias, se les hará el cargo que corresponde; y respecto a que según el estado que hoy tiene, aún no necesita nombrarse Alcaide de Alameda, se reserva ordenar para su tiempo y así mismo el asignar al celador, que se nombrare, el salario, que por su trabajo le corresponda (Archivo, p. 285-286).

El uso que se le dio al terreno, previo a la instauración de la Alameda, obedeció a las necesidades de la ciudad (principalmente de limpieza y almacenamiento de residuos). Se tiene en cuenta que el hecho de estar en las bifurcaciones del río (lugar donde corrían los residuos de la ciudad) limitaba considerablemente el empleo de construcciones dentro de él. Asimismo, por su localización fue aludido como una isleta en forma de herradura dentro de los límites de la ciudad. Es por eso que este lugar quedó fuera del crecimiento de por alrededor de dos siglos (en lo que manzanas nuevas corresponde). La incorporación de la Alameda no fue de los únicos cambios en la ciudad, las 


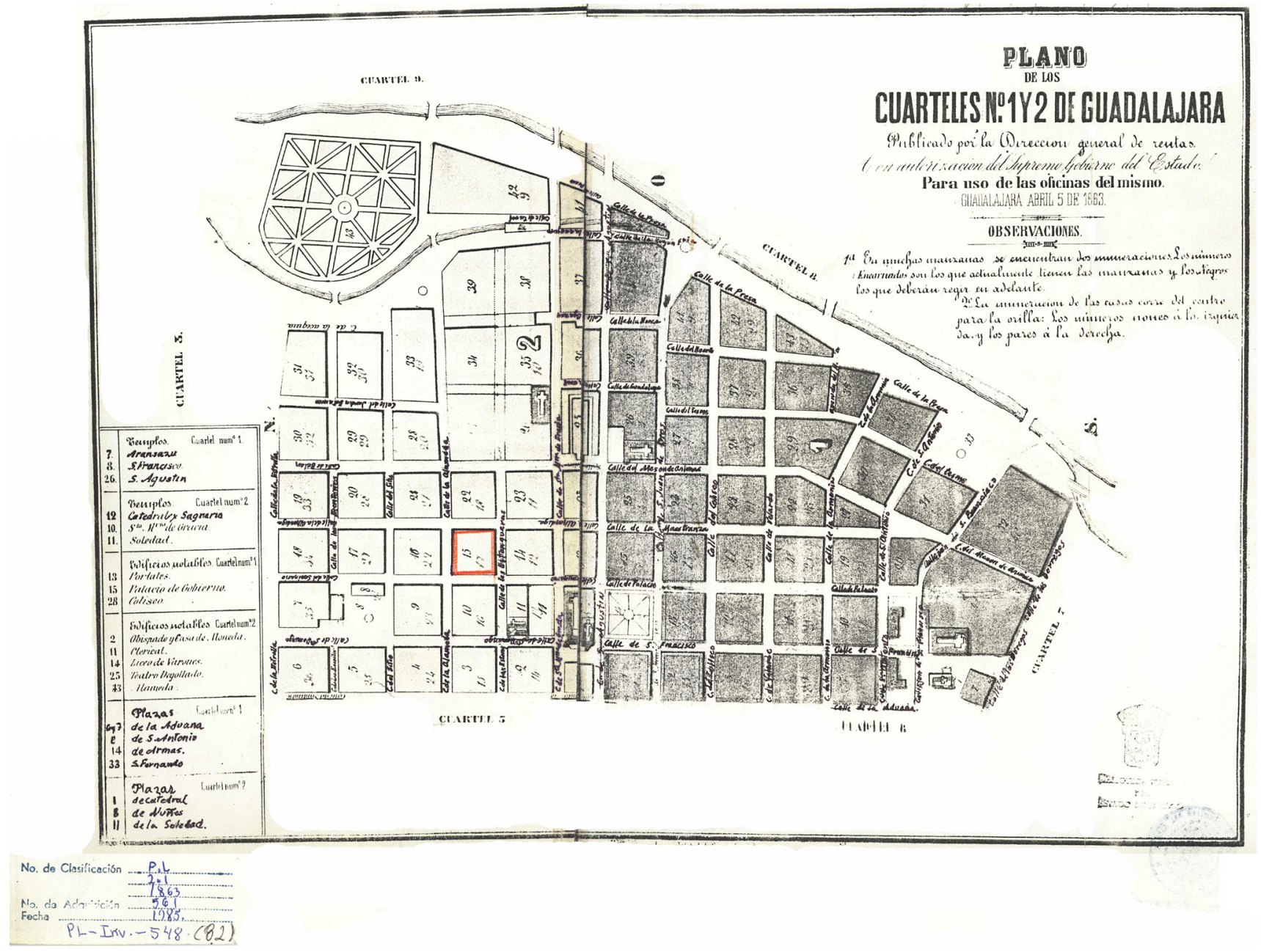

Imagen 01: Plano del cuartel núm. 1 y 2 del año 1863 donde se muestra la Alameda como parte del primer cuadro de la ciudad. Fuente: Archivo histórico del municipio de Guadalajara, referencia PL 2.11863561. reformas borbónicas impulsaron un cambio trascendente a las ciudades latinoamericanas y Guadalajara no fue la excepción. La transformación de la localidad competía a situaciones específicas como el saneamiento higiénico, moral y a su vez al incremento de seguridad por medio de un distinto control de barrios.

Las primeras décadas del siglo XIX trajeron consigo cambios en la morfología de la Alameda. Para el año 1863 ya estaba delimitada perimetralmente por un paseo que continuaba paralelamente al río San Juan de Dios con dirección al sur. En el interior, contaba con 14 andadores, tres en orientadas norte-sur, tres al oriente-poniente y ocho que se intersectaban diagonalmente en pares sobre cada uno de los 4 cuadrantes (imagen 01).

La Alameda como espacio público, satisfacía las prácticas sociales distintivas de la época. Al igual que la ciudad de México, la alameda de Guadalajara, en un principio y durante el siglo XVIII y XIX, era parte de las actividades de ocio y esparcimiento de la aristocracia de la ciudad. «Las relaciones y jerarquías sociales que se establecieron en la Nueva España y que se pueden apreciar en el paseo, el cual era utilizado por las clases altas conquistadoras no sólo para su ocio sino también como un sitio donde iban a exhibir su riqueza, mientras que los indígenas y esclavos estaban mayoritariamente en el pa- 
Imagen 02: Andador interior de la Alameda. Fuente: Secretaría de Cultura del Estado de Jalisco, referencia CPB482. seo para servir a sus amos y como comerciantes ambulantes» (Hernández, 20I2, p.I49).

Los habitantes tenían como costumbre acudir a la Alameda para exhibirse y conversar con otras personas de similares características socioeconómicas. Otra práctica era el cortejo entre integrantes de familias de abolengo. Las dinámicas desarrolladas son similares a las ostentadas en siglos anteriores en la ciudad de México y fue parte de la tendencia de reproducir los estereotipos europeos. La concurrencia a la Alameda tenía mayor auge en días específicos, principalmente los fines de semana, y dentro de una época del año definida (imagen 02).

El contexto general de la nación, durante el Porfiriato, tuvo dinámicas distintivas que hacían de las alamedas y paseos parte significativa en la cotidianidad de la población. Incluso, la forma de interactuar en estos lugares era característico y a su vez repetido a lo largo de las ciudades de la República Mexicana. En lo que respecta a las relaciones sociales, dentro de estos espacios públicos, nuevamente se menciona los días de mayor frecuencia y las acciones que acontecían dentro de él, primordialmente lo que respecta a las relaciones sentimentales.

La expansión industrial en la ciudad tuvo presencia también en las inmediaciones de la Alameda. Al oriente, del otro lado del río San

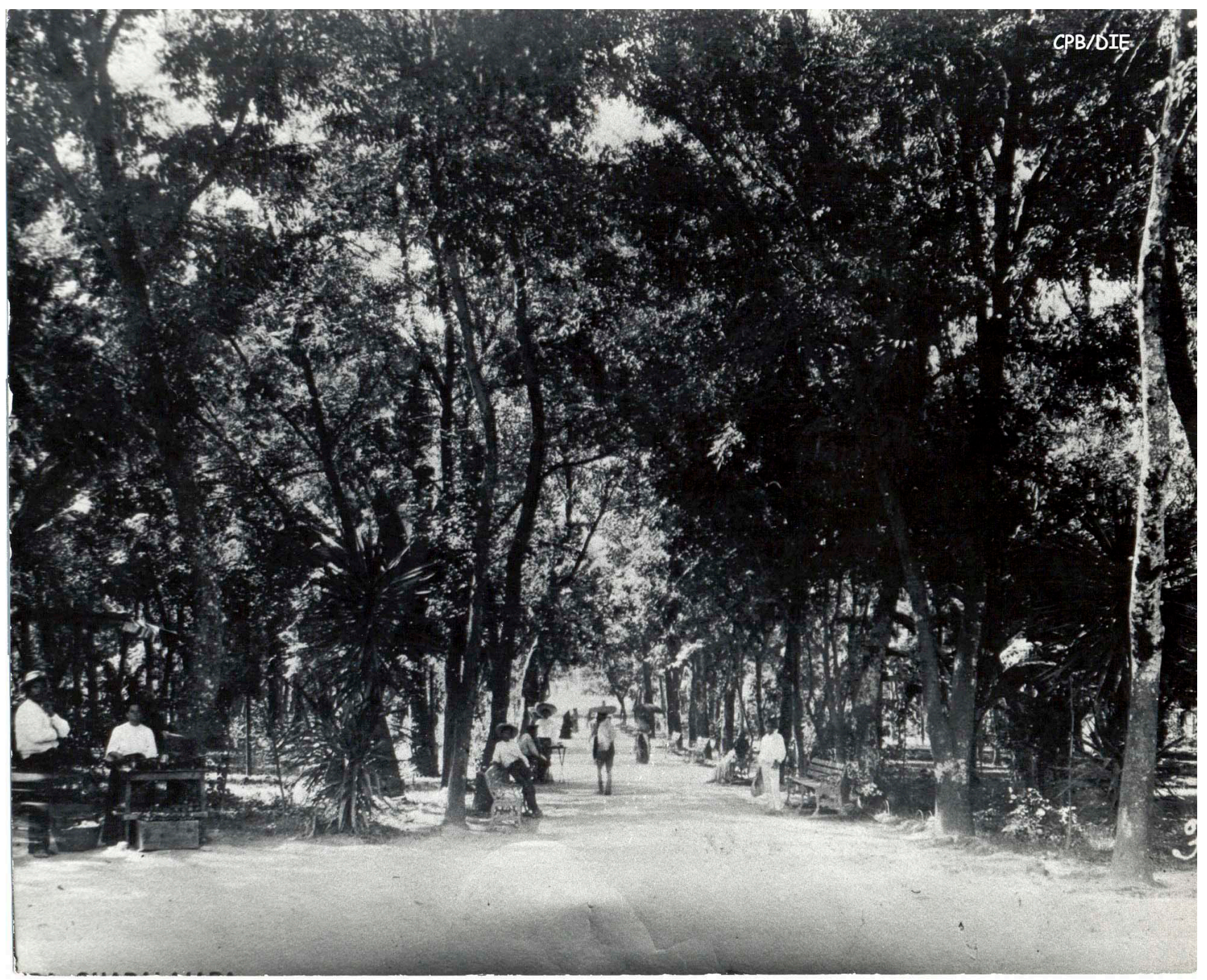


Juan de Dios, se estableció la cervecería La Perla en 1890 por Juan Orhner y después sería adquirida por José María Schnaider. Esta edificación dio paso a la posterior fundación de un jardín, espacio que en el siglo xx sería fusionado con la Alameda, y una colonia con el mismo nombre que permanece hasta la actualidad. Esta fase de progreso promovido fuertemente por el mandatario Porfirío Díaz, incrementó la creación de más vialidades, pavimentación y rectificación de trazos que favorecieran a un mejor aspecto y desplazamiento dentro la ciudad. Al cerrar el siglo, la Alameda mantenía su fisonomía sin grandes alteraciones. No fue sino hasta la tercera decada del siglo xx cuando cambió totalmente en forma y nombre.

\section{El valor social del conjunto de las esculturas juego del Parque Morelos}

La fundación del Parque Morelos en 1934, fue el inicio de una nueva configuración espacial del lugar. Los elementos recientes comenzaron a tener significados particulares para las personas que los utilizaban. Las familias que frecuentaron el parque durante la primera mitad del siglo xx, comenzaron a darle un significado a cada componente del lugar: fuentes, esculturas, mobiliario urbano y áreas verdes. Aquellos niños, que en su momento jugaron en las zonas infantiles y transitaban a los alrededores, pasaron a ser adultos y transmitieron el apego al lugar a nuevas generaciones. Los padres que llevaron a sus hijos, ahora son abuelos que asisten al Parque Morelos con sus nietos dando a entender que «el espacio urbano no es un texto ya escrito, sino una pantalla reestructurada permanentemente por una simbólica que cambia a medida de la producción de un contenido ideológico por las prácticas sociales que actúan en y sobre la unidad urbana» (Castells, I974, p.259).

En la segunda mitad del siglo xx, específicamente en el año 1965, se llevó a cabo la segunda intervención a gran escala en el Parque Morelos. Los trabajos estuvieron a cargo del ingeniero Aldo Córdova Fermanni en colaboración con el arquitecto Alejandro Zohn Rosenthal. Parte de la obra consistió en adicionar nuevos elementos, corredores y fuentes sobre las que en su momento estuvieron las diseñadas por el ingeniero Rafael Urzúa Arias. Además, se propuso una nueva área de juegos infantiles en el sector norponiente del parque. Para esto último se buscó la colaboración del arquitecto Fabián Medina Ramos en el año 1966. Al autor se le encomendó la tarea de diseñar una zona de juegos infantiles fuera de los convencionales de la época, columpios o resbaladeros. Esta zona se ubicaría aledaño al pabellón destinado para la fuente de sodas bajo el diseño del arquitecto Zohn. El resultado final de su propuesta consistió en grupo de esculturas juego compuesto por un caracol y ocho animales: hipopótamo, rinoceronte, oso, camello, jirafa, pez, serpiente y elefante, con acabados en concreto aparente, lo que, de acuerdo al autor, servirían para fomentar la imaginación de los niños al ellos proponer fantásticamente sus tonalidades (imagen 03 ). El proyecto «obedece a las ca- 


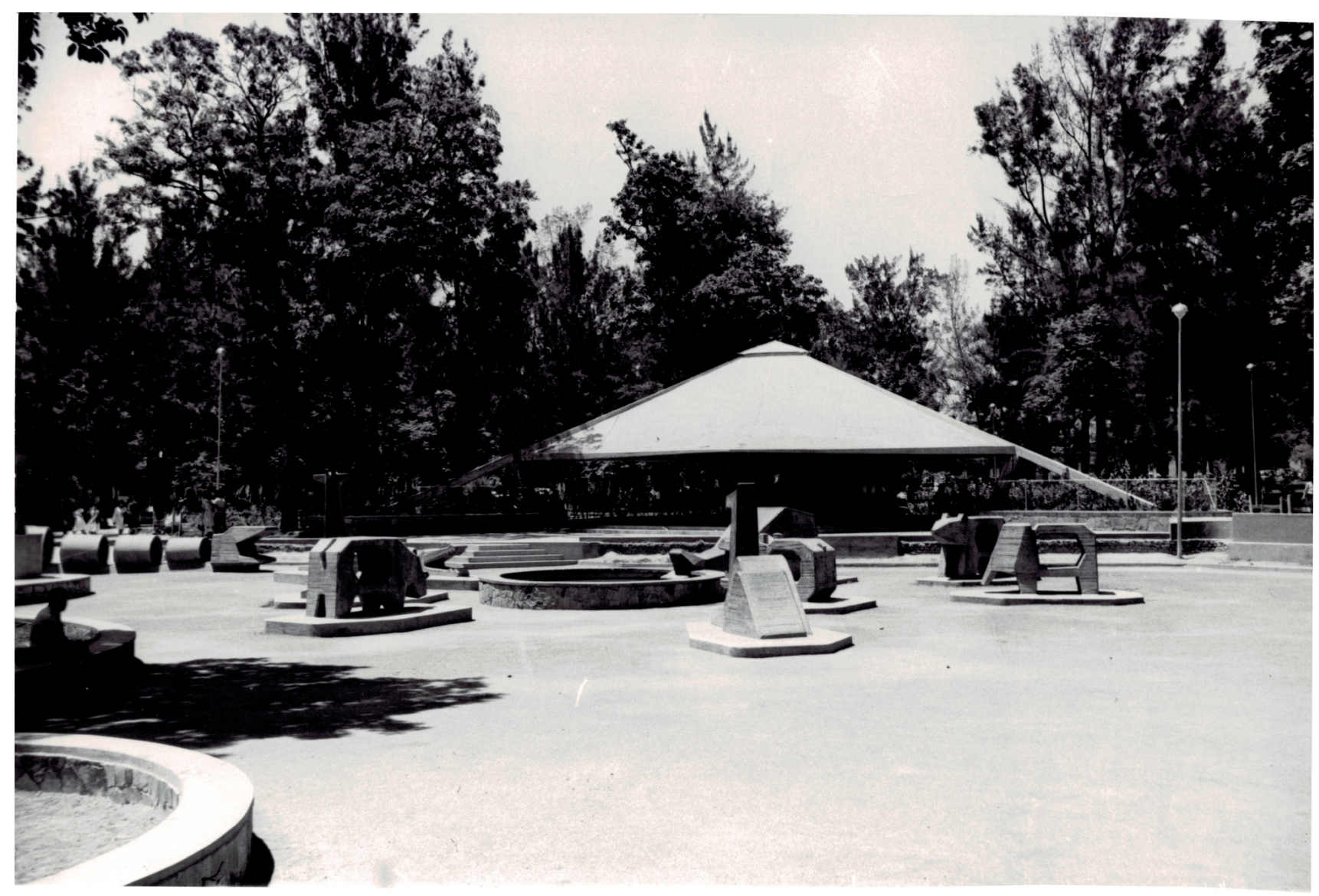

Imagen 03: Zona infantil en al norponiente del Parque Morelos. Fuente: Archivo personal del Arq. Fabían Medina Ramos. racterísticas, modalidades y costumbres propias de los niños de 3 a I 2 años de edad» (Arquine, 20I6, p.53). La conclusión del conjunto fue durante la primera mitad de 1966.

La reinauguración del Parque fue entre los meses de septiembre y octubre de 1966, donde «introdujo el lenguaje moderno al área infantil, lo que apunta a una idea integral del espacio público y la voluntad del arquitecto y el escultor por la creación de un mobiliario urbano experimental. Los juegos presentan una escala y ergonomía acorde a los usuarios niño, además de un tema más que recurrente y amigable en las áreas infantiles, las figuras de animales» (Solano, 20I8, p.67). En el año de 1967 el conjunto fue premiado con el segundo lugar el III Bienal Nacional de Escultura. La zona de las esculturas juego permaneció con las mismas características durante el remanente del siglo xx y en la primera década del xxi se implementó color a las esculturas.

Por su parte, la administración municipal de Guadalajara 20152018 comenzó con acciones en distintos puntos de la ciudad bajo su esquema de rescate de espacios públicos y dentro de la lista de lugares se encontraba el Parque Morelos. En agosto de 2016, la Dirección de proyectos del espacio público de la gestión integral de la ciudad presentó al gobierno municipal un proyecto conceptual de los trabajos a realizar en el parque. Una de las propuestas de mayor magnitud era la inserción de un ágora en la fracción norponiente del parque, donde se localizan el área infantil y el pabellón. Los primeros meses de trabajos avanzaron de forma periódica. Para entonces el proyecto conocido como rescate de espacios públicos pasaría ser denominado, Rea- 
Imagen 04: Celebración de los 50 años de la institución de las esculturas juego en el Parque Morelos. Fuente: del autor. condicionamiento y renovación de imagen urbana y paisaje del Parque Morelos, Durante el mismo periodo, ya avanzadas las labores en la sección norponiente, no existía una noción clara sobre los alcances y los beneficios del proyecto. Los habitantes, visitantes y comerciantes del lugar, manifestaron que la intervención no se socializó, la consulta pública fue nula y por lo tanto dudaban de sus bondades. La desconfianza y constantes quejas por parte de los vecinos, provocaron que se lanzaran varias peticiones y publicaciones por distintos medios suspendiendo parcialmente los trabajos.

Durante el periodo de receso se agregó otra denuncia sobre las propuestas del proyecto. En esta ocasión fue por el ágora sugerido en el extremo poniente del parque. Las esculturas de la autoría del arquitecto Fabián Medina Ramos corrían el riesgo de ser retiradas. El argumento inicial fue que el municipio tiene el derecho de resguardar la obra solicitada una vez entregada por el autor, pero, la realidad jurídica es que los derechos de la obra siguen perteneciendo al productor. Sobre esta sugestión, no era viable el hecho de retirar las esculturas o moverlas a otro punto. Posiblemente para los encargados de la propuesta, la conservación de estos elementos era irrelevante y carente de valor arquitectónico o artístico, pero, a pesar de ello no se podía tomar una decisión sin el debido consentimiento del autor y los habitantes del lugar.

Los vecinos del barrio El Retiro, profesionistas y otras organizaciones públicas y civiles presentaron un evento celebrando los 50 años de la inauguración del conjunto como método de protección enfocándose en dar a conocer el valor social que este espacio tiene pa-

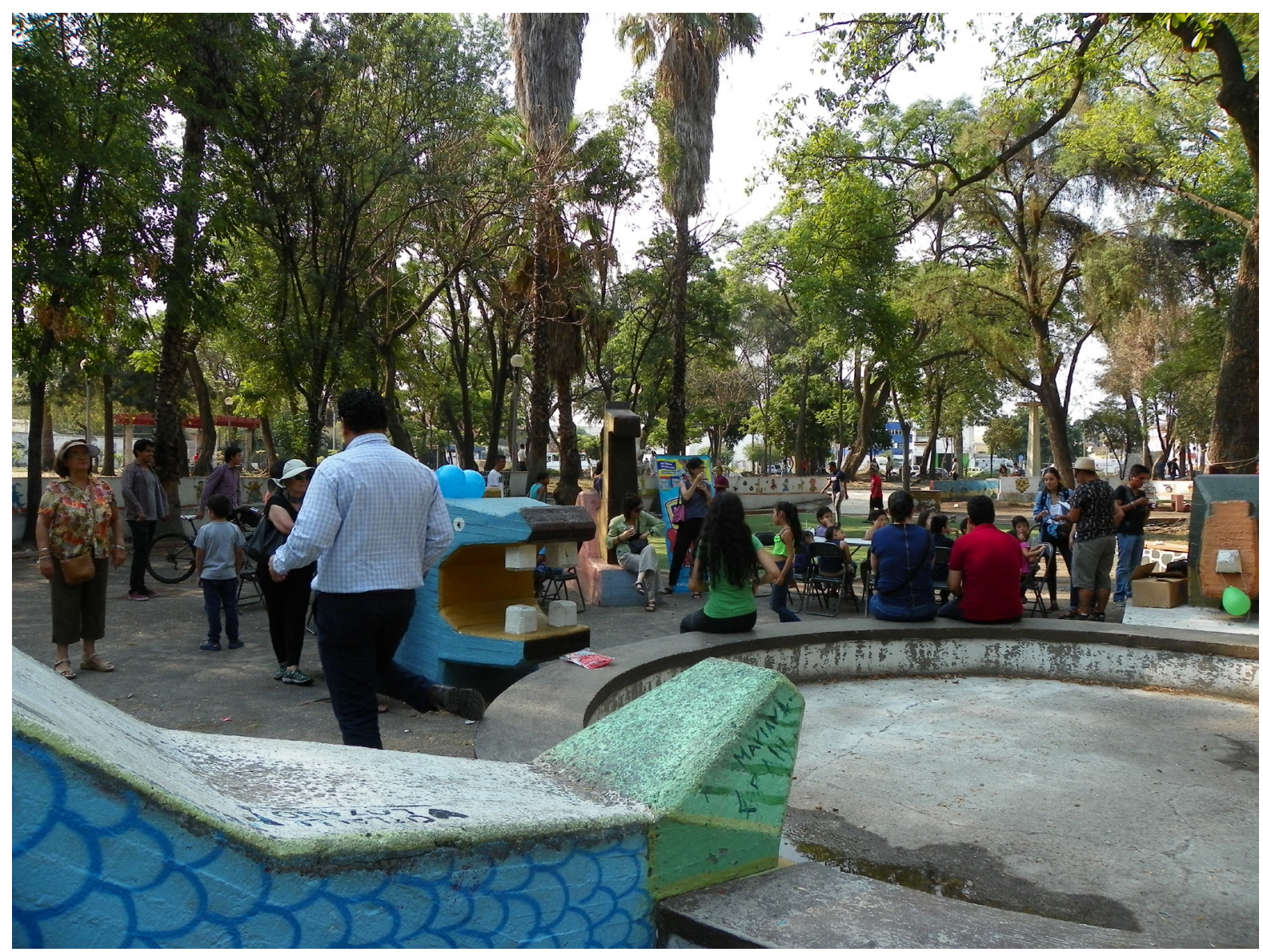



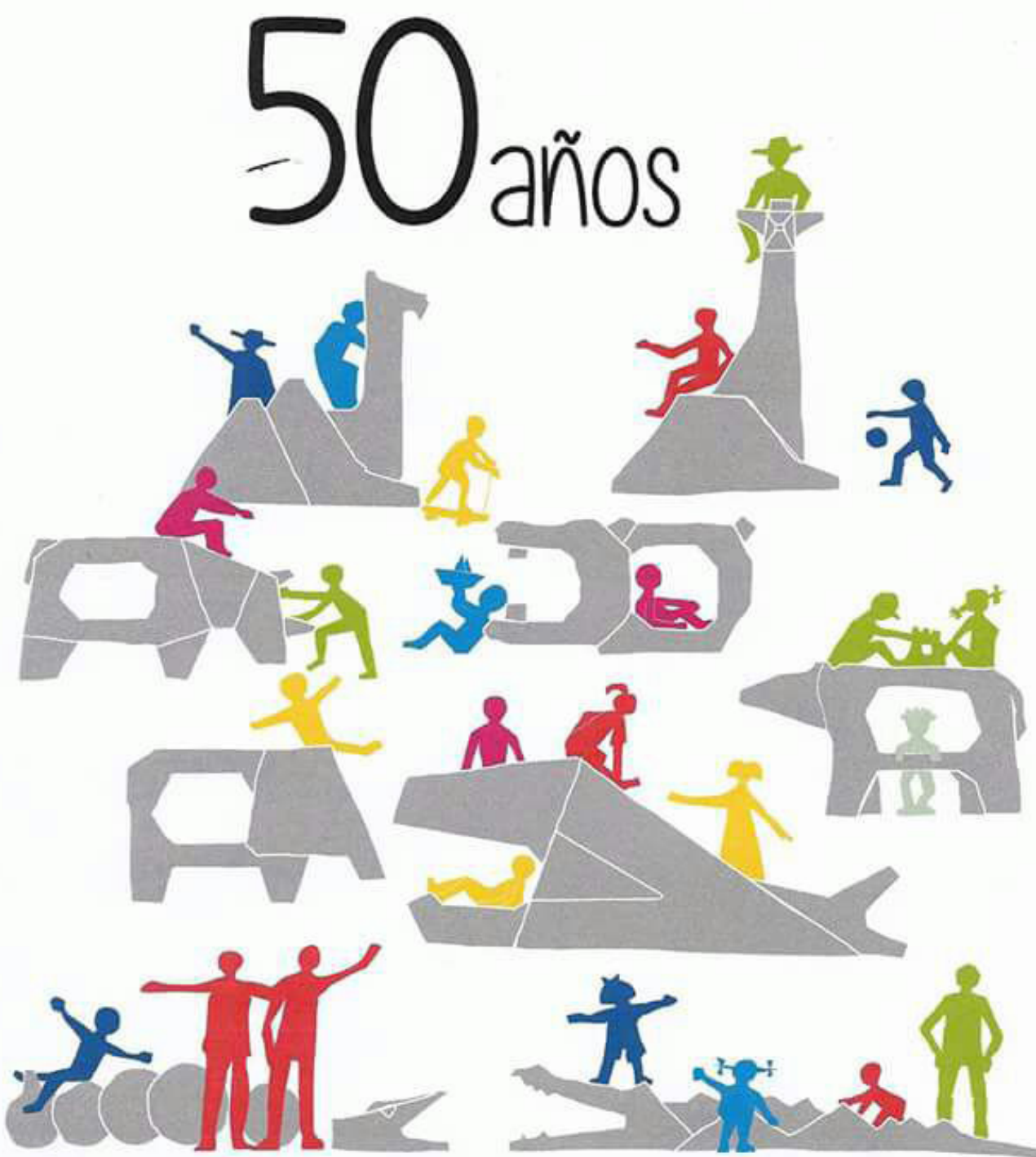

1967 -2017FSCCULTURSSUEECODELPARQUEEMORELOS celebración popular sàbad0 27 de mayo a partir de las 5:00pm talier in fanti de escultura / diáogo con fabián medina priàa y pastel / proyección documental / baiongo
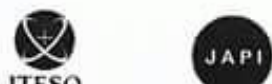


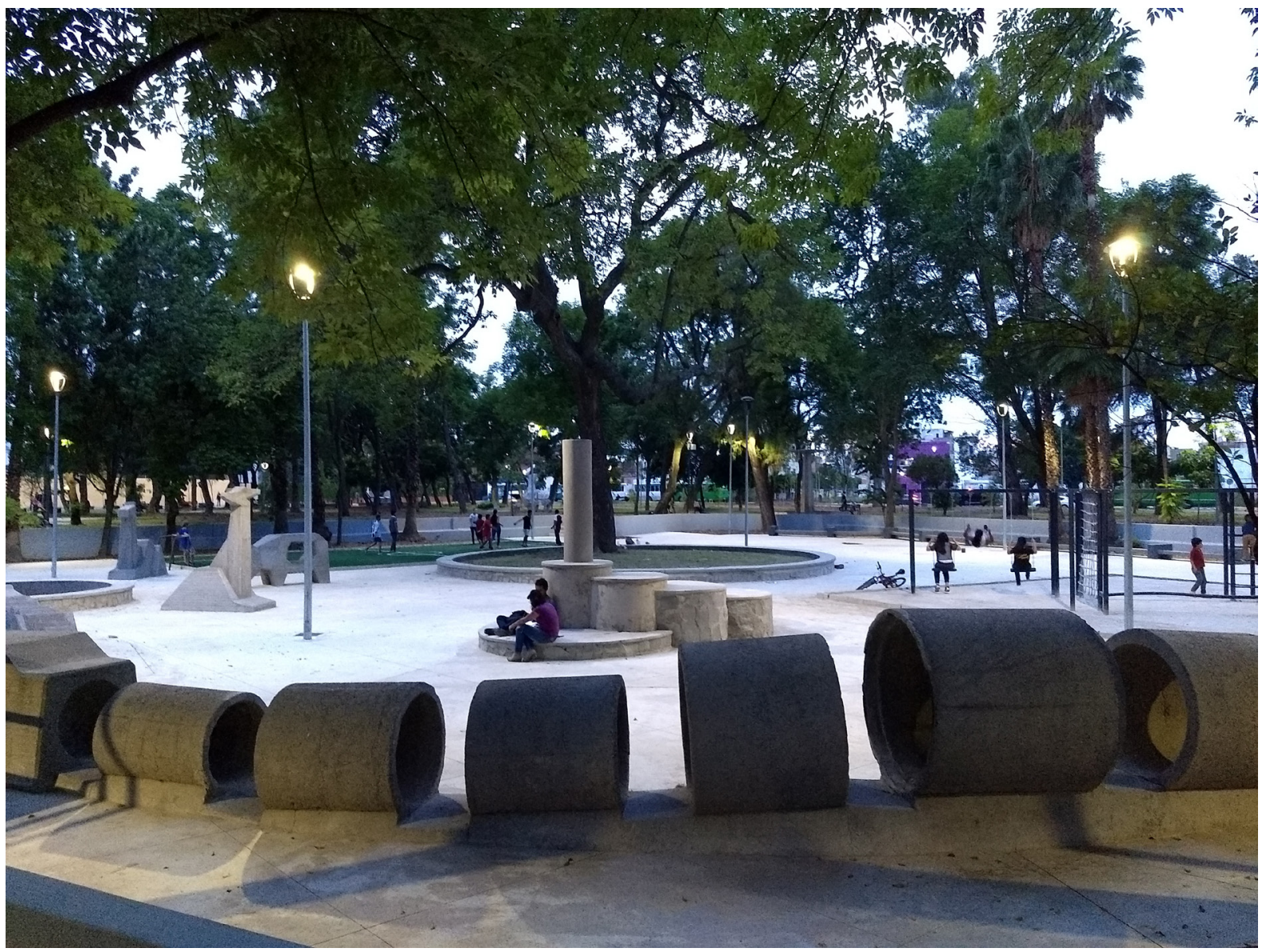

Imagen 06: Estado y uso actual de la zona infantil del Parque Morelos. Fuente: fotografía del autor. ra la comunidad (imagen 04). El evento se llevó a cabo el 27 de mayo de 2017 en la sección de las esculturas juego. «A modo de convocatoria Fabián Medina produjo un cartel en el que se anunciaron diversas actividades, todo con el apoyo solidario de diversos colectivos profesionales e instituciones educativas, entre ellas la Universidad de Guadalajara y el Instituto Tecnológico de Estudios Superiores de Occidente» (Cabrales, 20I9, p.26) (imagen 05). La asistencia de personas, al igual que diversos medios de comunicación fue considerable «las esculturas juego se vieron colmadas por adultos y niños que inyectaron algarabía a la fiesta. Fue posible identificar un cuadro social formado por personas vinculadas con las instituciones convocantes, periodistas y por supuesto gente de los barrios contiguos» (Cabrales, 20I9, p.26). El impacto del evento resultó en la suspensión definitiva de los trabajos en esta área. Así mismo, llamó la atención de habitantes de otros puntos que desconocían este lugar y posteriormente asistieron a visitarlo.

Los trabajos en el Parque Morelos continuaron después del evento, excluyendo al conjunto de esculturas y el pabellón de alguna alteración a su integridad física. Posteriormente se propuso la intervención de esta zona con el propósito de restaurar los elementos deteriorados bajo la supervisión del autor. Las esculturas se liberaron de las capas de pintura con la finalidad de regresarlas a su estado inicial y las integraron con otros espacios de esparcimiento infantil. Por su parte, el pabellón fue consolidado y restaurado en sus cubiertas y espacios interiores (imagen o6). La conclusión de la obra no sólo consistió en las labores manuales sino en la incorporación del conjunto al inven- 
tario del patrimonio cultural del Estado de Jalisco el 20 de enero de 2018. Este panorama resultó totalmente distinto a lo que la administración y su grupo de profesionistas plantearon en primera instancia. Este espacio no había sido contemplado para ser declarado, pero, los habitantes demostraron el valor social que este lugar posee. Es por ello que el fomentar y difundir el uso de este atributo para la protección, apego y pertenecía de espacios públicos es ineludible.

El conjunto del pabellón y los juegos infantiles muestra la conjunción de la arquitectura y la escultura que ha dejado, en los habitantes y usuarios, un sin número de anécdotas y experiencias que se alojan en la memoria colectiva. Todas estas experiencias vividas y el hecho de transmitir las costumbres a las generaciones posteriores, brindan un valor social significativo, que mediante sus manifestaciones socioculturales les brinda difusión y protección. Es por ello que los encargados de las intervenciones en espacios del bien común deben de contemplar y analizar mediante distintos métodos los valores que un espacio patrimonial posee ya que la finalidad de una propuesta es beneficiar principalmente a los primeros involucrados o actores sociales que conviven diariamente en el lugar. De otra forma, se continuará con la mala práctica que fragmenta el tejido social, la interacción entre habitantes y la continuidad de dinámicas transmitidas a generaciones posteriores.

\section{A manera de conclusión}

La visión contemporánea no siempre se enfoca en la búsqueda de los valores arraigados en el espacio si no en el cambio de imagen esperando que por medio de esta se solucionen problemáticas sociales y patologías urbanas. El patrimonio urbano tiene una identidad que se ha forjado por su permanencia a través de los años, sin descartar que se modifica por los estilos de vida y la dinámica social. La permanencia no sólo marca el valor histórico del lugar. El paso del tiempo y las actividades sociales que se establecen se convierten, en algunas ocasiones, en tradiciones y eventos simbólicos que posteriormente marcan la identidad del lugar y en los habitantes crea una pertenencia y apego al espacio.

Los sentidos primarios como la pertenencia y apego son la materia prima para la protección de los espacios públicos. Posteriormente, se solicita de difusión de los valores que posee. La valoración social como medio de protección del patrimonio urbano genera un aprecio y cuidado de los elementos urbano-arquitectónicos simbólicos y significativos. Para tener el aprecio de la colectividad no es indispensable que el elemento cumpla con ciertas características estéticas o una imponencia monumental ya que se valúa conforme al uso lúdico. Entonces, tanto puede importar una pequeña escultura como una edificación de dimensiones considerables siempre y cuando exista un uso y los habitantes sientan un aprecio por él. La valoración social no sólo 
aplica al patrimonio edificado o tangible, también lo intangible posee un fuerte arraigo que se debe de conservar y divulgar.

El desconocimiento por parte de las autoridades e involucrados en los proyectos y tomas de decisiones pudieron haber llevado al conjunto a desaparecer. Resulta preocupante que hasta la fecha de los trabajos se desconociera el hecho que los elementos tuvieron un galardón en el III Bienal Nacional de Escultura y fueran significativos para la sociedad. De igual manera, la composición física de las esculturas y el pabellón muestran un valor tecnólogo por la incursión de elementos de concreto en esa temporalidad. Esta ausencia de divulgación, documentación y sensibilidad al patrimonio ha sido la causante de la pérdida de edificaciones, objetos y actividades que fueron parte de la historia de la ciudad y complemento de la identidad local. Tal como se señaló, el patrimonio moderno está susceptible a cualquier cambio inapropiado por la baja protección que la ley les brinda.

La valoración es indispensable a pesar que los procesos de estudio tomen un tiempo adicional previo a la propuesta conceptual de intervención. El uso de equipos interdisciplinarios es importante para llegar a una finalidad en común que realmente beneficie a los habitantes. La sociedad es la que mayormente tiene el conocimiento de las problemáticas urbanas y como se podrían llegan a soluciones compatibles con la realidad del lugar. En muchas circunstancias no se requiere del derroche de altas sumas de dinero proveniente del erario público, sino de acciones puntuales que mejoren y fortalezcan la calidad de vida y los valores que se tienen.

El valor social del conjunto de esculturas juego en el Parque Morelos comienza a observarse desde la preocupación y protección demostrada por los vecinos del barrio El Retiro, las asociaciones civiles, instituciones educativas y habitantes de otros puntos que han disfrutado del lugar desde hace tiempo. La permanencia de actividades y manifestaciones socioculturales también marcan un valor simbólico y significativo. En su momento, cuando fue la Alameda, el paseo dominical era parte de los referentes simbólicos. A partir de la segunda mitad del siglo xx, la feria del cartón se convirtió en otra manifestación con el Parque Morelos y su contexto. También la referencia actual está en las nieves raspadas o las tardes bohemias en el interior del pabellón fuente de sodas donde se reúnen semanalmente a bailar danzón, al igual que la zona de juegos infantiles. Tal como se mencionó, cada actor social le brinda el valor simbólico y significativo correspondiente a la actividad que desarrolla o recuerda. La importancia recae en la permanencia que tengan dichas expresiones socioculturales y su trascendencia a futuras generaciones que, en su momento, serán los responsables de la conservación del lugar y sus actividades.

La relación entre los habitantes y el conjunto denotaron los valores sociales que concluyeron en la protección, restauración y declaración del conjunto como patrimonio cultural del Estado. La relevancia de la valoración social se manifestó por medio de las acciones consumadas dónde también se reforzó la interacción entre vecinos y organismos públicos y privados que buscan el mismo fin, la salvaguarda de su patrimonio urbano ante intervenciones sin previo estudio y con- 
sideración del significado del lugar. La presencia social en defensa de su patrimonio urbano y pertenencia del mismo expuso que las organizaciones vecinales pueden llegar a tener un poder ante propuestas que no se relacionen con ellos.

La trascendencia del lugar se percibe mediante las personas que lo aprecian. En este caso en particular llamó la atención como un conjunto de modesta escala propicio un movimiento importante que expresó la valoración social del lugar y se propago a otros espacios públicos donde las soluciones propuestas por la administración municipal no convenían a las necesidades de las comunidades vecinas. Se espera que en un futuro cercano se contemple la valoración y el análisis histórico y social de los lugares a intervenir ya que los que disfrutaran de los beneficios propuestos serán los habitantes y aquellos usuarios que lo utilizan paulatinamente. También, es indispensable fomentar, por medio de los valores sociales, que los espacios públicos son necesarios para la convivencia colectiva donde actualmente los nuevos puntos de centralidad como centros comerciales han ganado importancia dentro de la interacción social.

Las dinámicas urbanas cambian constantemente al igual que la percepción del esparcimiento y ocio de los habitantes. El espacio público se encuentra compitiendo contra lo ofrecido por los centros comerciales y espacios abiertos dentro de asentamientos fortificados. Se olvida que los espacios públicos ofrecen la identidad de la urbe y son ellos los que propician convivencias. La valoración social no sólo busca que el espacio se vea en condiciones habitables sino también que se regrese y fomente el permanecer y utilizar estos lugares. El esparcimiento dentro de los espacios públicos es benéfico para la interacción social es por ello que la conservación de estos lugares es indispensable. Un lugar donde se observa la interacción social atrae a más usuarios e incrementa la pertenencia. Por otro lado, si no se considera su valor social puede caer al abandono, malas prácticas sociales o intervenciones sin sentido por parte de las administraciones gubernamentales. Todos tienen el derecho de estar en un espacio público digno, pero también de fomentar sus valores hacia futuras generaciones. Apropiarse genera pertenecía y mayor resguardo porque la valoración social es una peculiaridad que caracteriza el lugar, pero también es algo que le favorecerá a la continuidad a través del tiempo. 


\section{Bibliografía}

Arquine. (2016). Guía de arquitectura. Guadalajara, (pp. 50-53). México: Arquine S.A. de C.V.

Allier, J. (2016). Derecho patrimonial cultural mexicano, crítica a la normatividad vigente, (pp. 40-46). México: Editorial Porrúa.

Ballart, J. (1996). El valor del patrimonio histórico. En Complutum Extra, núm. 6 (pp. 215-224). En línea: <https://revistas.ucm.es/index. $\mathrm{php} / \mathrm{CMPL} /$ article/view/CMPL9696330215A>

Becerril, J. (2003). El derecho del patrimonio histórico-artístico en México, (pp. 1-11). México: Editorial Porrúa.

Archivo municipal de Guadalajara. Papeles de derecho de la audiencia de la nueva Galicia, tomo IV, exp. 814.

Bernal, B. (2016). La construcción del espacio a partir de la experiencia de habitar. En Espinosa (Coord.), Espacio, cultura e interacciones sociales, (pp. 165-183). México: Universidad Autónoma Metropolitana, unidad Xochimilco.

Cabrales, L. (2019). Salvaguarda de un patrimonio de la modernidad en Guadalajara: El zoológico de cemento, (pp. 1-26). Guadalajara: Universidad de Guadalajara.

Castells, M. (1974). La cuestión Urbana, (pp. 240-259). España: Siglo XXI editores.

Cottom, B. (2008). Nación, patrimonio cultural y legislación: los debates parlamentarios y la construcción del marco jurídico federal sobre monumentos en México, siglo XX, (pp. 240-266). México: Cámara de Diputados LX Legislatura y Miguel Ángel Porrúa.

De las Rivas Sanz, J. (1992). El espacio como lugar: sobre la naturale$z a$ de la forma urbana, (pp. 1-38). Valladolid: Universidad de Valladolid.

Gómez, L. (2009). Documentos internacionales de conservación y restauración, (pp. 290-294). México: Instituto Nacional de Antropología e historia.

Hernández, A. (2012). Pintura y paisaje: un recorrido por la Alameda Mexicana. En Cuadernos Geográficos, núm. 51, 144-156. En línea: $<$ http://www.redalyc.org/articulo.oa?id=17125450010>

Jokilehto, J. (2016). Valores patrimoniales y valoración, (pp.-126). En Revista de conservación INAH, núm. 2. En línea: <https://revistas.inah.gob.mx/index.php/conversaciones/article/ view/10884/11652>.

Solano, A. (2018). Playgrounds del México moderno, (pp. 65-67). México: Cubo blanco.

Suárez, C. (2016). Espacios abiertos patrimoniales, (pp. 1-42). México: Universidad Nacional Autónoma de México, 2016.

Velasco, M. (2015). La percepción de la violencia desde la lectura de los espacios urbanos agresivos. En De la Torre (Coord.), Violencia ciudad y territorio, (pp. 83-98). México: Miguel Ángel Porrúa.

Weibel, H. (2018). Patrimonio moderno y sentido de pertenencia. El caso de la Plaza de Armas, Osorno Chile. En Arquitectura y Urbanismo, vol. XXXIX, núm. 2. En línea: <https://www.redalyc.org/ jatsRepo/3768/376858946002/html/index.html $>$. 